\title{
DOS CABEZAS CORTADAS ATRIBUIBLES A LUISA ROLDÁN EN LA HISPANIC SOCIETY OF AMERICA
}

\author{
Alfonso Pleguezuelo \\ Universidad de Sevilla \\ aplegue@us.es
}

\begin{abstract}
Aumentar el número de obras de esta autora es el objetivo de este artículo en el que se proponen dos que pudieron haber salido de sus manos: las cabezas cortadas de San Juan Bautista y San Pablo que se conservan en la Hispanic Society of America, de Nueva York. Un análisis formal de sus rasgos y su comparación con obras documentadas o adjudicadas con seguridad, pretenden fundamentar esta nueva atribución. De forma paralela, se reflexiona sobre el posible origen sevillano del tema iconográfico que representan.
\end{abstract}

Palabras clave: Luisa Roldán; La Roldana; Cabezas cortadas; Santos decapitados; Barroco; Naturalismo.

\section{TWO SEVERED HEADS ATTRIBUTABLE TO LUISA ROLDÁN IN THE HISPANIC SOCIETY OF AMERICA}

Augmenting the number of works safely attributable to Luisa Roldán is the aim of this study. The author considers two sculptures that may have come from her hands: the severed heads of Saint John the Baptist and Saint Paul, in the collection of the Museum of The Hispanic Society of America, Nueva York. Formal analysis and comparison with securely documented works serve to substantiate the attribution. In addition, the possible Sevillian origin of this iconographic type is examined.

Key words: Luisa Roldán; La Roldana; severed heads; decapitated saints; Baroque; Naturalism.

Luisa Roldán (1654-1706), más conocida por su apodo familiar "La Roldana” e hija del célebre escultor Pedro Roldán (1624-1699), es una artista del Barroco sevillano que en los últimos años ha sido objeto de un creciente interés en medios científicos ${ }^{1}$. Las investigaciones más rigurosas han debido enfrentarse al problema del elevado número de obras de dudosa atribución que siguen aún hoy provocando una visión confusa de sus auténticas aportaciones. No obstante, con esfuerzo, este escollo está siendo superado a nivel académico al ir formándose un catálogo más depurado que confirma obras documentadas o de atribución segura, descarta otras más discutibles y añade algunas hasta ahora desconocidas o atribuidas a otros artistas ${ }^{2}$. En esa modesta pero necesaria tarea

\footnotetext{
${ }^{1}$ La producción bibliográfica sobre esta artista hasta 2007 quedó recogida en Romero Torres y Torrejón Díaz, 2007.

2 Pleguezuelo, 2009: 27-53; Dobado, 2009: 196-197; Romero, 2009: 166-179; Herrera García y Pérez de Tena, 2011: 59-68; Pleguezuelo, 2011: 80-93; Pleguezuelo, 2012: 275-300.
} 
debe inscribirse este artículo en el que pretendemos dar a conocer dos nuevas obras que pudieron haber salido de sus manos: las cabezas cortadas de San Juan Bautista y San Pablo que se conservan en la Hispanic Society of America, de Nueva York, obras que hasta ahora habían permanecido desvinculadas de su catálogo.

Gracias a la fina sensibilidad de Archer Milton Huntington (1870-1955), estas dos esculturas ingresan y son registradas en el museo por primera vez en $1920^{3}$. Diez años más tarde, Proske llamó la atención sobre ellas, datándolas a fines del siglo XVII y considerándolas con certera intuición, obras cercanas a la producción de Pedro Roldán o de su escuela ${ }^{4}$. La misma autora insiste en trabajos posteriores sobre el interés de estas esculturas y su genérica atribución ${ }^{5}$. Martín González, quien probablemente las conoció a través de la publicación de la autora americana, menciona sólo la de San Juan Bautista y, sin llegar a atribuirla, la data también en el siglo XVII ${ }^{6}$. En 1993, sin ser exhibidas, fueron reproducidas e incluidas en el apéndice final del catálogo de una exposición organizada por el Spanish Institute, al cuidado de Suzanne Stratton quien mantuvo la datación y el origen sevillano sugeridos inicialmente por Proske ${ }^{7}$. A pesar de ello, ningún autor posterior que se ha ocupado de la figura de Pedro Roldán ha incluido estas obras en su catálogo ${ }^{8}$. En efecto, ambas piezas, puestas en relación con el resto de su producción conocida, plantearían serias dificultades para ser integradas en su quehacer en tanto que coinciden, a nuestro entender, de forma mucho más nítida con el estilo interpretativo de su hija Luisa. Por todo ello, se proponen aquí por vez primera como obras de esta artista, tomando como base, ante la carencia de firma, de documentación directa o de pruebas analíticas, razones estilísticas que se detallan más adelante y que otros autores podrán contrastar en el futuro ${ }^{9}$. En caso de que esta propuesta fuese aceptada, podríamos añadir dos nuevas obras de gran calidad al catálogo de esta escultora con el valor añadido de constituir las primeras de su producción con esta iconografía tan vinculable al barroco andaluz.

Con independencia del lugar geográfico en que fueran realmente modeladas, teniendo en cuenta que La Roldana vivió sucesivamente en Sevilla, Cádiz y Madrid, es preciso comentar que ciertas peculiaridades iconográficas de este conjunto permiten considerarlo, como ya sugería intuitivamente Proske, aún sin ofrecer argumentos, producción artística vinculada a Sevilla ${ }^{10}$. El motivo esencial que podríamos aducir para defender tal idea sobre su origen es el hecho -bastante infrecuente en el resto del arte español antes del siglo XVIII- de que aparezcan asociadas y con un tratamiento formal muy similar las cabezas de ambos personajes a los que tan sólo uniría teóricamente el hecho circunstancial de haber sido martirizados, como otros muchos santos cristianos, mediante la decapitación.

La representación de la cabeza cortada del Bautista, como tema independiente, es un asunto propio de todo el arte cristiano desde época bizantina y aumentó la frecuencia de su aparición a fines de la Edad Media y durante la Moderna, convirtiéndose en un tema preferente del ámbito anglo-germánico durante el Gótico y también del italiano y del español durante el Barroco, dos

\footnotetext{
${ }^{3}$ Sus números de inventario en el referido museo son respectivamente D-823 (San Juan) y D-824 (San Pablo).

${ }^{4}$ Proske, 1930: 301 y 303, Plates XXV, XVI, CXXVII y CXXVIII.

${ }^{5}$ Proske, 1938: 90 y 1954: 255. Sin embargo, la autora no llega a mencionar estas obras en su excelente artículo sobre la etapa madrileña de Luisa Roldán, publicado en 1968.

${ }^{6}$ Martín González, 1957: 210 y 213.

7 Stratton, 1993: 176.

${ }^{8}$ Roda, 2012.

9 Debo expresar un particular agradecimiento hacia Patrick Lenaghan, conservador de La Hispanic Society of America, por su extrema amabilidad, sus valiosos comentarios y sus inestimables ayudas en el reconocimiento de estas obras y de otras de la misma artista que se custodian en la Hispanic Society de Nueva York. Igualmente, mi gratitud hacia Peter Cherry quien generosamente me hizo útiles observaciones a la lectura del primer borrador de este artículo.

${ }^{10}$ Agradezco también, en este sentido, las utilísimas sugerencias de Juan Randado Pérez.
}

Arch. esp. arte, LXXXIX, 353, ENERO-MARZO 2016, 29-42 ISSN: 0004-0428, eISSN: 1988-8511, doi: 10.3989/aearte.2016.03 


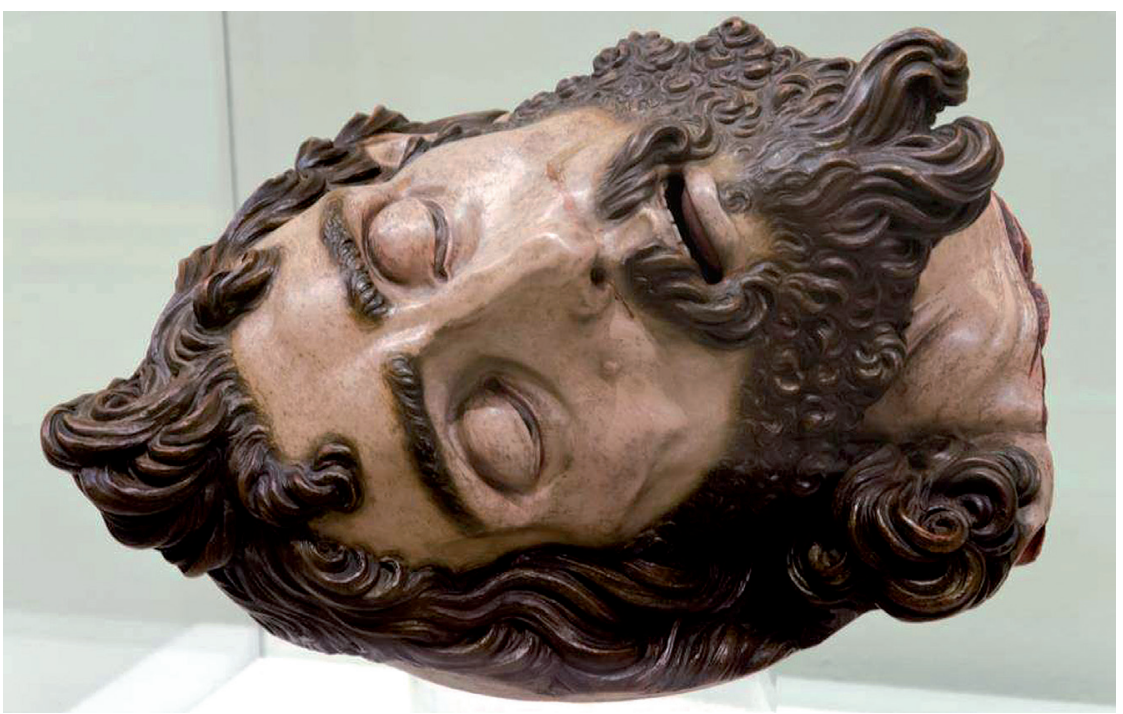

Fig. 1. Gaspar Núñez Delgado. Cabeza de San juan Bautista. Museo de Bellas Artes. Sevilla.

periodos particularmente proclives a rememorar los episodios más cruentos de las escrituras sagradas. También hubo representaciones durante el Renacimiento, artísticamente impecables aunque carentes del dramatismo de las versiones del medioevo y de las del siglo XVII. No ha sido este tema iconográfico asunto estudiado con detalle en el arte del barroco hispánico hasta muy recientemente ${ }^{11}$.

El de los santos decapitados, en general, fue un tema recuperado con entusiasmo desde finales del siglo XVI gracias, probablemente, a las directrices de Trento y a la cruda sensibilidad naturalista de Caravaggio de quien no se conocen cuadros con este tema concreto aunque sí se han establecido paralelos con su Cabeza de Medusa ${ }^{12}$. Lo cultivan, por el contrario, sus seguidores, cuyas obras pronto debieron ser conocidas en España. Recordemos las dos interpretaciones pictóricas de la cabeza cortada de San Juan Bautista, hechas por Ribera hacia 1646, que hoy forman parte de las colecciones de la Real Academia de San Fernando, de Madrid, y del Museo Civico Gaetano Filangeri, de Nápoles, respectivamente.

Las propias representaciones sevillanas barrocas en escultura son tempranas si consideramos la impresionante cabeza cortada de San Juan Bautista que modela en terracota Gaspar Núñez Delgado, firmándola y datándola en 1591, hoy exhibida en el Museo de Bellas Artes de Sevilla ${ }^{13}$ (fig. 1). Es evidente la deuda de esta obra de Núñez con otra anterior, de igual tema, atribuida a Juan de Juni, que se conserva en el museo de la catedral de Valladolid ${ }^{14}$. Es probable que Núñez

${ }^{11}$ Gracias a la amable indicación de mi colega Roberto Alonso, he tenido acceso a la obra aún inédita de Requena Bravo de Laguna, 2012. En uno de los capítulos de este trabajo se aborda en particular la iconografía de las cabezas cortadas y se hacen novedosas aportaciones al respecto. Una reciente publicación acomete la interpretación de este tema en el arte de la Edad Media y de inicios del Renacimiento: Baert, 2013: 117-160. Véase también Gregori, 2007: 353-364.

${ }^{12}$ No consideramos en este caso su obra Salomé con la cabeza de San Juan Bautista conservada hoy en el Palacio Real de Madrid en la que aparecen varias figuras además de la cabeza del Bautista sobre el plato al igual que ocurre con el cuadro, firmado, de la Decapitación del Bautista y conservado en el Oratorio de la catedral de San Juan Bautista de la ciudad de La Valetta, en Malta.

${ }^{13}$ La obra, que posee una extensa bibliografía reciente, fue referida por vez primera por Gestoso, 1909: 150-151.

${ }^{14}$ Boletín de la Sociedad Española de Excursiones, 1898: 134

Arch. esp. arte, LXXXIX, 353, ENERO-MARZO 2016, 29-42

ISSN: 0004-0428, eISSN: 1988-8511, doi: 10.3989/aearte.2016.03 


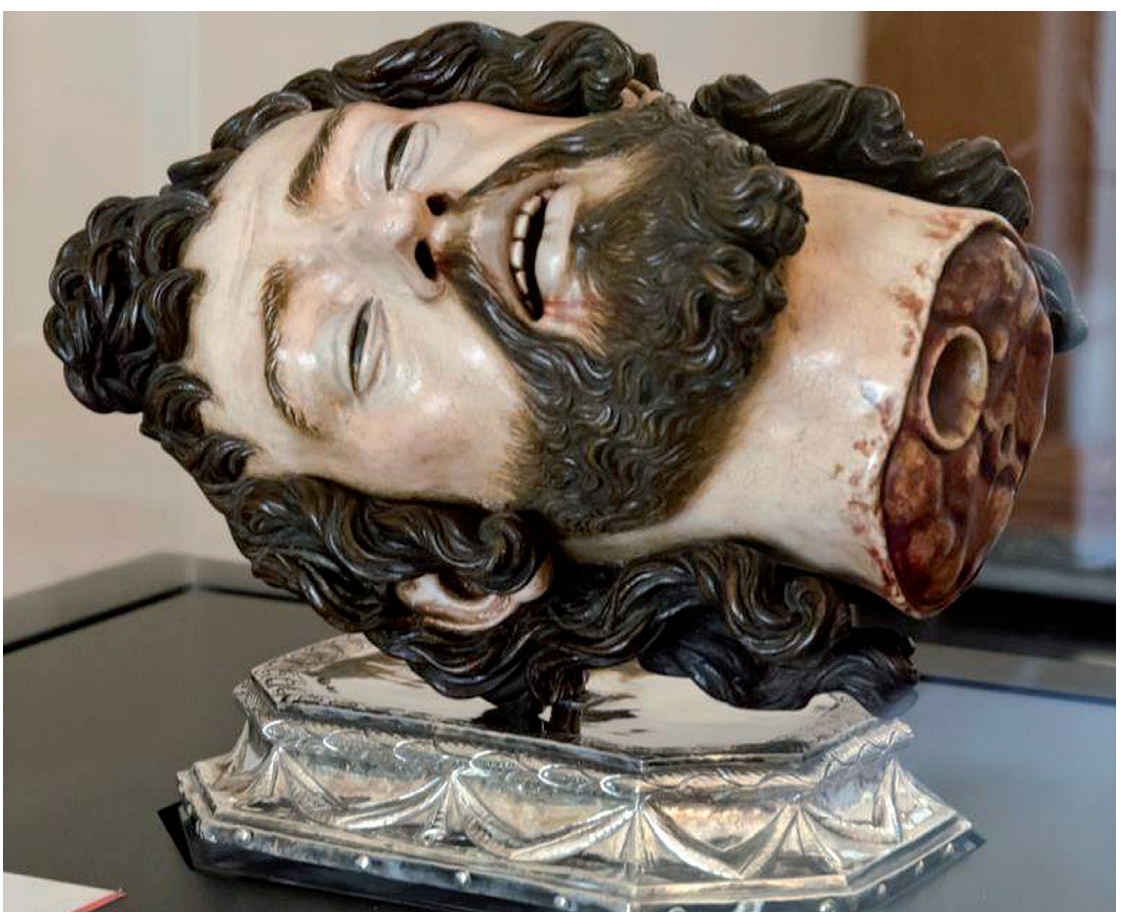

Fig. 2. Juan de Mesa (atrib.). Cabeza de San Juan Bautista. Museo de la Catedral de Sevilla.

Delgado no llegara a conocer el libro de Pacheco Arte de la Pintura, inédito hasta 1649, en el que se describen las facciones que debe mostrar el rostro del Precursor, pero sí conoció al autor y sus ideas puesto que el suegro de Velázquez policromó más de una de sus esculturas, entre otras, la imagen del Bautista para el convento sevillano de San Clemente, hecha por el escultor en $1613^{15}$. Al leer los párrafos del erudito pintor sevillano, son muchos los paralelos que se observan con la citada interpretación que Núñez había hecho años antes ${ }^{16}$.

También otros escultores sevillanos, después de Núñez, abordaron el mismo tema, a veces, integrado física e iconográficamente en retablos dedicados al Protomártir del Cristianismo. Es el caso, entre otros, de la cabeza cortada de San Juan Bautista que talla Juan Martínez Montañés entre 1614 y 1617 para el retablo dedicado a este santo en el convento de Santa Clara, o también el que hace en 1621 para el de San Leandro o la que esculpe Felipe de Ribas para el monasterio de Santa Paula, en 1637, todos ellos en Sevilla. Pero también en otros casos, los artistas de este mismo círculo interpretaron el asunto como obra exenta; tal es la cabeza del Bautista que se conserva en el Museo de la Catedral de Sevilla, atribuida con fundamento a Juan de Mesa quien, como artista más inclinado que los anteriores al primer Naturalismo, realiza en esa obra una versión de extraordinaria fuerza dramática (fig. 2). También serían bastante abundantes fuera de Sevilla las obras posteriores de este tema, algunas de ellas firmadas o atribuidas a artistas de renombre como Alonso de Villabrille y Ron, Juan Pascual de Mena, Juan Antonio Ron, Felipe de Espinabete, el granadino Torcuato Ruiz del Peral o el aragonés José Ramírez Benavides de quien

\footnotetext{
${ }^{15}$ Sobre la obra de Gaspar Núñez Delgado, autor que aún carece de un estudio monográfico, puede consultarse el trabajo de Luna Moreno, 2008-2009: 379-394 así como el artículo de Alonso Moral, 2010: 533-556, trabajo éste último que recoge la bibliografía anterior. Mi gratitud a Roberto Alonso por sus valiosas ayudas bibliográficas para este artículo.

${ }^{16}$ Pacheco, 1990: 662.
} 
se conserva una pareja de cabezas de San Juan y San Pablo en la basílica del Pilar, de Zaragoza, datada ya en 1753 .

Es probable que este ambiente favorable a representar la cabeza del santo esté relacionado no sólo con la devoción que éste inspiraba o con la vieja y extendida leyenda según la cual aliviaba la migraña sino también con el auge general del culto a las reliquias y con el debate que en ese momento se intensifica acerca de la verdadera ubicación de la cabeza del Bautista que se disputaban, entre otras muchas sedes, la iglesia de San Silvestro in Capite o San Giovanni dei Fiorentini, en Roma, la catedral de Amiens, la Sainte Chapelle, de Paris, la iglesia de San Lorenzo, en Génova, San Marcos, en Venecia o el monasterio de Studios, en Constantinopla ${ }^{17}$.

Por su lado, la figuración independiente de la cabeza decapitada de San Pablo, aunque bastante menos frecuente que la anterior, es relativamente habitual en el arte europeo, en el español y, sobre todo, en el andaluz. Pero la formación de una pareja pictórica o escultórica con ambas testas es bastante más rara; al menos, no ha llegado al presente ninguna datable antes de mediados del siglo XVII ${ }^{18}$. Tampoco conocemos versiones fuera de España anteriores a ese momento. Es significativo que en Malta, isla en la que coinciden por razones diferentes las dos devociones, no se haya conservado ni un solo conjunto en el que se vinculen las cabezas de ambos personajes ${ }^{19}$.

Todo parece indicar, pues, que la asociación de las cabezas cortadas de San Juan y San Pablo fue una aportación inicial de la pintura barroca sevillana ya que son varios pintores de esta escuela y momento los principales cultivadores del asunto. Entre las primeras interpretaciones pictóricas es mencionada una de Francisco de Herrera, el Viejo (ha. 1590-ha 1656), datable, según Martínez Ripoll, hacia 1650-54, aunque tan sólo se conserva localizada hoy la de San Pablo, en el Museo del Prado $^{20}$. Las primeras parejas completas, firmadas y datadas, son de dos posibles discípulos suyos: Juan Valdés Leal (1622-1690) y Sebastián de Llanos Valdés (ha. 1605-1677) ${ }^{21}$. La más temprana es la que el primero de ellos pinta para el retablo del convento del Carmen, en Córdoba, conjunto contratado en 1655 y concluido poco después. Y aquí es preciso recordar que la relación entre la Roldana y Valdés fue muy estrecha pues el pintor fue padrino de una de sus hermanas y asiduo colaborador de su padre al policromar algunos de sus conjuntos escultóricos más importantes $^{22}$. Por otro lado, Luis Antonio Navarro de los Arcos, suegro de Luisa, fue maestro pintor y colaborador personal del mismo Valdés en varios encargos como, por ejemplo, las pinturas para el claustro de la Casa Profesa de la Compañía de Jesús, en Sevilla, en $1676^{23}$. De todo ello hemos de deducir que Luisa, desde joven, debió mantener un contacto muy directo con Valdés Leal y su obra y, con seguridad, conoció otros posibles cuadros que éste pudiera haber pintado con la citada

${ }^{17}$ Reau, 1995: 510-518.

${ }^{18}$ No debe extrañarnos esta doble asociación pues fueron frecuentes las parejas de otros santos decapitados como Cosme y Damián, Emeterio y Celedonio, Nabor y Félix, Proto y Jacinto etc. Tampoco eran ajenas al arte sevillano otras parejas de santos aunque, a diferencia de los anteriores, no hubiesen sido decapitados. Los propios patronos locales como Santas Justa y Rufina, San Isidoro y San Leandro o San Hermenegildo y San Fernando eran personajes emparejados por distintas razones que familiarizaron a los devotos locales con estas asociaciones dúplices entre las que la de San Juan y San Pablo sería, simplemente, una más. Es probable que el auge de los retablos también favoreciera estos pareados que tan fácilmente se adaptarían a los esquemas iconográficos simétricos de estos muebles litúrgicos.

${ }^{19}$ La importancia que adquiere en Malta la Orden de San Juan hace que la catedral de su capital, La Valetta, esté dedicada a este santo y que sean abundantes las obras que narran su vida y su muerte. Por otro lado, la circunstancia de que San Pablo, en su viaje por el Mediterráneo, naufragara en las costas de esta isla y viviera un tiempo allí, también provocó que se le dedicara un templo y numerosas imágenes pictóricas y escultóricas. En diferentes iglesias de la isla hay interpretaciones de las cabezas cortadas de uno y de otro santo pero ninguna pareja en que aparezcan asociadas.

${ }^{20}$ Su pareja no fue adquirida, según decisión de Pérez Sánchez referida por Martínez Ripoll, por causa de su mal estado de conservación. Martínez Ripoll, 1978: 161-162.

${ }^{21}$ Valdivieso, 2000: 314-315.

${ }^{22}$ Sancho Corbacho, 1950: 234.

${ }^{23}$ Gestoso, 1917: 127.

Arch. esp. arte, LXXXIX, 353, ENERO-MARZO 2016, 29-42

ISSN: 0004-0428, eISSN: 1988-8511, doi: 10.3989/aearte.2016.03 
temática. Tal vez el propio Murillo con quien Luisa debió tener también contacto muy directo, pudo interpretar este tema aunque no conocemos ningún ejemplo ni tampoco sabemos quién fue el autor de dos cabezas cortadas que poseía Nicolás de Omazur, cliente y amigo del pintor ${ }^{24}$.

A pesar de este testimonio temprano de Valdés Leal, será Sebastián de Llanos, artista del mismo círculo, el pintor que más se destacará en la interpretación de este tema que se hará muy popular en Sevilla en sus versiones pictóricas. De hecho, la segunda pareja de cabezas cortadas que tenemos firmada y fechada es la que se conserva en la iglesia Colegial del Salvador, de Sevilla, que éste pinta en $1670^{25}$, fecha aproximada en que Luisa inicia su trayectoria profesional independiente. No sería, por tanto, de extrañar que la Roldana, formada en Sevilla junto a estos pintores, decidiera en algún momento de su carrera realizar una interpretación escultórica del tema. Pero, si a partir de mediados del siglo son numerosas las parejas de lienzos que se han conservado representando este asunto, tan sólo conocemos como interpretación escultórica del siglo XVII esta pareja de la Hispanic Society, lo que la convierte en un conjunto de enorme valor documental ${ }^{26}$.

Los textos sagrados en que se apoya la escueta descripción del martirio de San Juan son bien conocidos: la obra de Flavio Josefo ${ }^{27}$ y los evangelios de Marcos (6: 14-29) y de Mateo (14: 112). En todos ellos se narra cómo el Tetrarca de Galilea, Herodes Antipas, había mandado encarcelar a Juan en la fortaleza de Macarea aunque sentía por él un respeto que le disuadía de condenarlo a las penas máximas que se le podían aplicar por sus provocadoras predicaciones. El precursor de Cristo, en más de una ocasión, había recriminado a Herodes haber tomado por esposa a Herodías, sobrina suya y mujer de su propio hermano, lo que había suscitado en ésta un odio feroz hacia el Bautista. Un día de banquete, en el clima de entusiasmo provocado por el vino y por la seductora danza de Salomé, hija de Herodías, comentó Herodes a la bella muchacha para complacerla que daría satisfacción a cualquier deseo que le expresara. Salomé consultó a su madre quien aprovechó la ocasión para deshacerse del incómodo profeta que pretendía apartarla de su amante. Herodes se vio en la disyuntiva de faltar a su palabra o aceptar la petición y se inclinó por esto último, ordenando la decapitación cuando corría el año 36 después del nacimiento de Cristo.

De esta historia bíblica, descrita con diversos matices narrativos en los tres textos mencionados y con enorme fortuna plástica en multitud de obras de arte, se deriva la representación de este episodio que queda reflejado de forma sintética y con especial austeridad en la escultura que aquí comentamos. La obra de la Hispanic Society sigue el modelo iconográfico habitual pero de forma especialmente sobria y elegante, dado que, a excepción del plato, prescinde de otros atributos específicos (figs. 3 y 4). En él figura tan sólo la cabeza del último de los profetas y primer mártir cristiano, algo girada, sobre un paño azul extendido, a su vez, sobre la metálica bandeja ${ }^{28}$.

La decapitación de San Pablo no es un episodio narrado en los evangelios sino en los textos del Pseudo Dionisio Areopagita quien recoge la biografía del llamado "apóstol de los gentiles". Según este autor, Pablo, llamado Saulo de Tarso, de origen judío pero helenizado, pasó de ser perseguidor a perseguido, fue detenido durante el mandato de Nerón y decapitado hacia el año 67. Según la leyenda, el golpe seco de la espada provocó en el corte del cuello un repentino borbotón de sangre

\footnotetext{
${ }^{24}$ Kinkead, 1986: 82-83.

${ }^{25}$ Valdivieso, 1991: 94.

${ }^{26}$ Resulta llamativo que tampoco se conozcan más versiones escultóricas sevillanas exentas de este asunto durante los siglos XVII y XVIII.

${ }^{27}$ Flavio Josefo, 2002: cap. 18, ver.2.

${ }^{28}$ La cabeza de San Juan mide $49 \mathrm{~cm}$. de diámetro y $21,5 \mathrm{~cm}$. de resalte máximo. El modelo ornamental del plato reproducido en estas dos obras es retardatario respecto de la fecha de la escultura puesto que se trata de un tipo que fabricaban los plateros de Sevilla desde inicios del siglo XVII en un estilo sobrio y desornamentado que tenía su origen en el clasicismo imperante de ese momento. No debe extrañar, no obstante, este aparente anacronismo que también reflejan los testimonios pictóricos de esta misma fecha.
}

Arch. esp. arte, LXXXIX, 353, ENERO-MARZO 2016, 29-42 ISSN: 0004-0428, eISSN: 1988-8511, doi: 10.3989/aearte.2016.03 


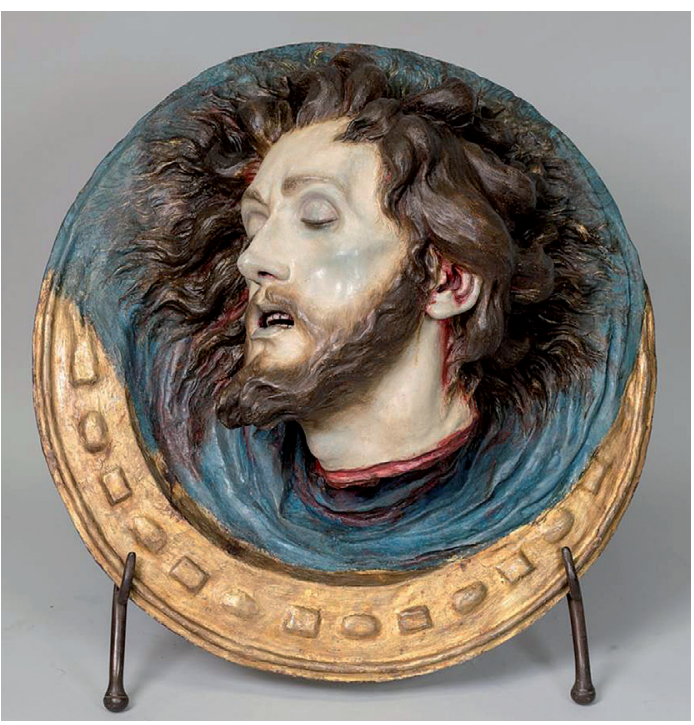

Fig. 3. Luisa Roldán. Cabeza de San Juan Bautista. Hispanic Society of America. Nueva York (Foto: Patrick Lenagham).

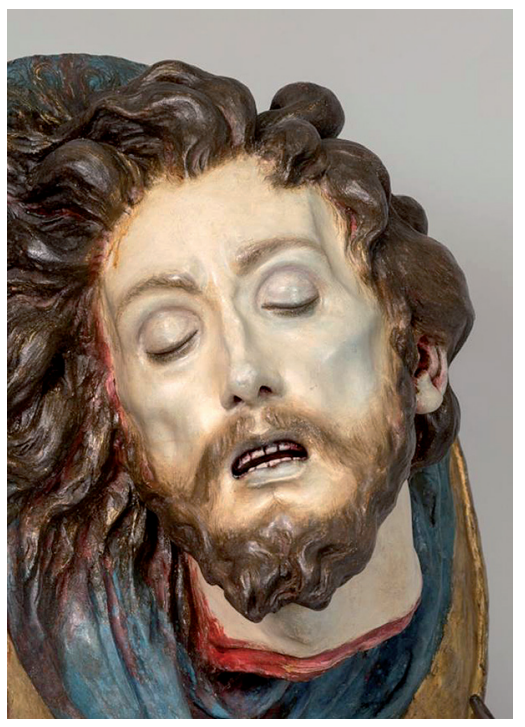

Fig. 4. Luisa Roldán. Cabeza de San Juan Bautista. Hispanic Society of America. Nueva York Detalle (Foto: Patrick Lenagham).

mezclada con leche y, además, la cabeza cayó chocando tres veces contra el suelo y allí donde impactaba brotaba un agua cristalina. En la interpretación que del tema hace Valdés Leal en el citado retablo de Córdoba, por ejemplo, se representan, surgiendo de la tierra, tres manantiales en tanto que en esta versión escultórica se prefirió representar más bien el momento en que la supuesta leche brota de la herida y se derrama sobre el paño, también azul, que cubre el plato ${ }^{29}$. El efecto del líquido blanquecino se ha logrado en este caso empleando un pan de plata visible entre las pinceladas de azul ${ }^{30}$. Representar la cabeza de San Pablo, al igual que la de San Juan, sobre otro plato en lugar de hacerlo sobre la tierra, obedece a una licencia iconográfica que tan sólo vemos empleada en las versiones andaluzas de este tema y que resulta poco fiel a los textos aunque favorece la relación estética de las dos cabezas (figs. 5 y 6 ).

El hecho de que ambas estén dirigidas en sentidos opuestos está en relación con la probable ubicación original que tuvieron, enfrentadas una a otra, tal vez en el interior de urnas, quedando San Pablo a la izquierda y San Juan, a la derecha aunque es posible que la posición de estas obras fuese horizontal y no inclinada como se muestran en la actualidad, siguiendo un patrón expositivo que suponemos posterior al siglo XVIII ${ }^{31}$.

Dada esta tradición andaluza de emparejar las cabezas de San Juan y San Pablo y constatada en otros ejemplos pictóricos, nada debe extrañar que Luisa Roldán, formada en Sevilla en el círculo de los artistas que realizan esta heterodoxa interpretación del tema, lo abordara haciéndose eco de

${ }^{29}$ La cabeza de San Pablo mide $47 \mathrm{~cm}$. de diámetro y $19 \mathrm{~cm}$. de resalte máximo.

30 Agradezco a Hélène Fontoira, restauradora encargada por la Hispanic Society de la cuidadosa limpieza de estas dos obras, el haberme facilitado medidas y otros detalles materiales de las mismas.

31 Es muy probable que los actuales soportes de hierro fuesen añadidos posteriormente para dar a estas obras la inclinación que sería habitual desde el siglo XVIII y que, por cierto, provocan una percepción bastante diferente de la que producirían en origen al disminuir su verismo por obvias razones de gravedad y acercar su visión al campo de la pintura o del relieve parietal.

Arch. esp. arte, LXXXIX, 353, ENERO-MARZO 2016, 29-42

ISSN: 0004-0428, eISSN: 1988-8511, doi: 10.3989/aearte.2016.03 


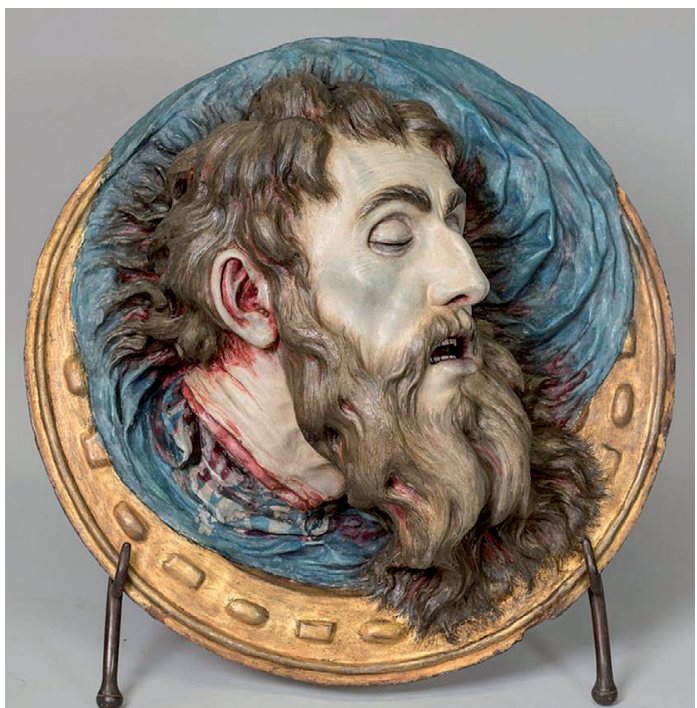

Fig. 5. Luisa Roldán. Cabeza de San Pablo. Hispanic Society of America. Nueva York (Foto: Patrick Lenagham).

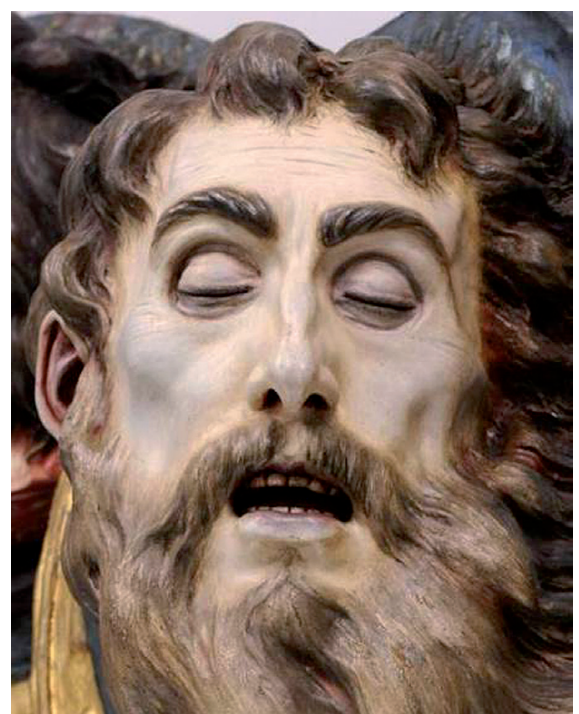

Fig. 6. Luisa Roldán. Cabeza de San Pablo. Hispanic Society of America. Nueva York. Detalle (Foto: Patrick Lenagham).

esa fórmula en una magnífica versión modelada en terracota. No hay indicios suficientes para determinar si estas dos obras, que revelan una extraordinaria madurez artística, fueron hechas durante su periodo andaluz o en la posterior etapa madrileña puesto que la Roldana muestra sus peculiares maneras de hacer desde su primera etapa hasta el final de su vida. No obstante, una interesante noticia publicada en 1981 por Mercedes Agulló permite contemplar la posibilidad de que sean obras hechas en Madrid, ciudad donde la artista tanto usó este material. Según esta noticia, Julián Moreno de Villodas, secretario del Ayuntamiento de Madrid durante el reinado de Felipe V, habría recibido de su mujer Maria Manuela Gutiérrez de Carriazo, por escritura de capital a su favor, hecha el 16 de junio de 1731: "Dos cabezas de San Pedro (sic) y San Juan, de barro, de mano de la Roldana, en sus urnas, 1800 rs" ${ }^{32}$. Es evidente que el escribano confundió a San Pedro con San Pablo ya que cuando en 1751 se redacta el inventario de los bienes de Villoda, se mencionan: "Dos cavezas de San Pablo y San Juan, de mano de la Roldana, 2200 rs",33. No podemos asegurar que se trate de las obras que aquí atribuimos a la autora aunque esa posibilidad es muy verosímil y, sobre todo, la noticia deja constancia documental de que Luisa Roldán abordó este tema y en este mismo material. Llama la atención comprobar que estas cabezas estuvieron acompañadas en la colección de Villoda por esculturas de Pedro de Mena y por pinturas de Durero, el Greco, Tiziano, Tintoretto, Caravaggio, Velázquez, Van Dick, Murillo etc. Todo ello puede tomarse como indicio del nivel de valoración que recibían las obras de Luisa Roldán en la corte.

Ambas cabezas fueron modeladas en arcilla y vaciadas con el fin de evitar agrietamientos durante la cocción. A pesar de ello, algunas fisuras se produjeron durante el horneado del que también quedó como indicio una superficie oscurecida por el humo en la concavidad del reverso, especialmente en el caso de la cabeza de San Juan ${ }^{34}$.

\footnotetext{
${ }^{32}$ Agulló, 1981: 227.

${ }_{33}$ Barrio Moya, 1989: 608.

${ }^{34}$ Un eventual análisis de la pasta cerámica de estas dos piezas, si pudiese ser comparado con la de otras obras firmadas de la misma autora, podría confirmar si sus respectivas composiciones mineralógicas son coincidentes y también
} 


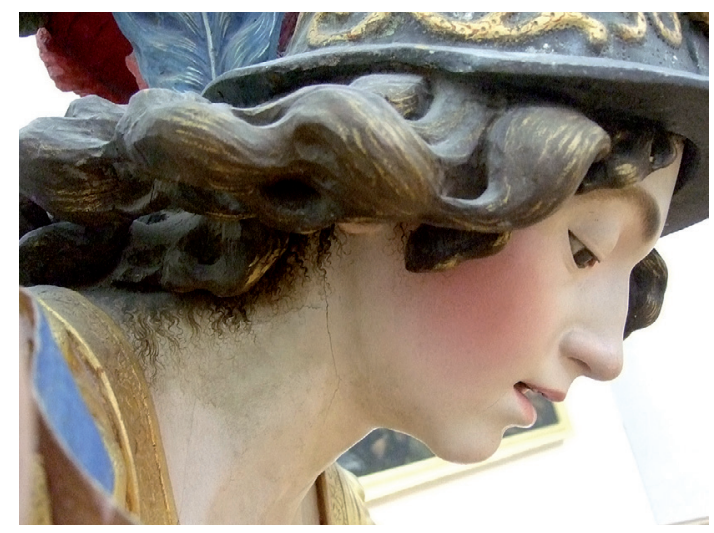

Fig. 7. Luisa Roldán y Thomas de los Arcos. San Miguel. San Lorenzo de El Escorial (Foto: Alfonso Pleguezuelo).

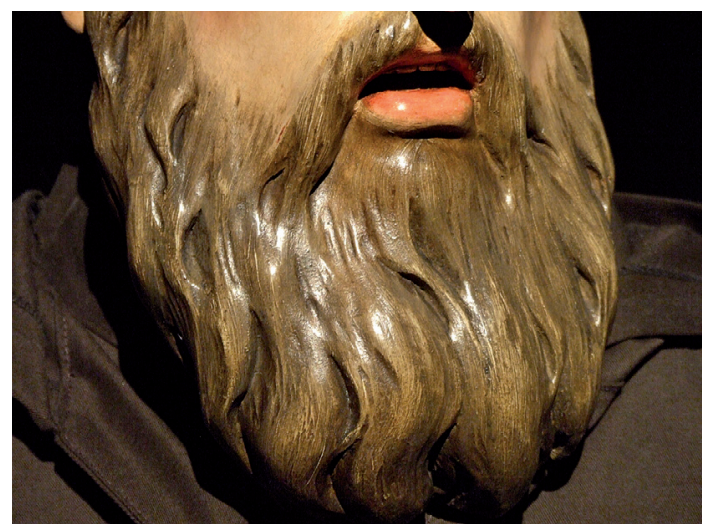

Fig. 8. Luisa Roldán. San Francisco de Paula. Iglesia del antiguo convento de la Victoria. Puerto Real (Cádiz) (Foto: Alfonso Pleguezuelo).

Sorprende en estas obras la precisión con que establece la diferencia del tratamiento de los rasgos faciales de ambos personajes, relacionada con la distinta edad que se supone tenían en el momento del martirio. No sólo se percibe ello en el hecho de que San Juan posee el cabello castaño en tanto que San Pablo lo muestra ya poblado de canas y con un tono general ceniciento sino en otros detalles más sutiles como la tersura de la piel del Bautista frente a las arrugas de San Pablo; las cejas, apenas insinuadas con leves pinceladas en el caso del Precursor pero densamente pobladas en el Apóstol de los gentiles, o el tamaño de la nariz y las orejas, aumentados en el caso del santo de mayor edad (fig. 6). Todo denota un estudio minucioso de la anatomía humana propio de alguien que ha madurado esa disciplina académica y que posee, además, una notable capacidad de observación del natural.

La forma inflada de los mechones de las cabelleras responde a la misma solución que la Roldana da a la melena de la imagen de San Servando, de Cádiz, a la de los Niños Nazarenos, de San Fermín de los Navarros, de Madrid y de San Antón, de Granada, o a la de San Miguel, de El Escorial (fig. 7). Esta fórmula tan personal y cuya fuente de inspiración aún desconocemos, constituye uno de los rasgos más originales e identificativos de su labor y distingue muchas de sus esculturas respecto de las de sus colegas contemporáneos andaluces y cortesanos. Hay en la sinuosa y delicada forma de tallar o modelar estos cabellos algo de oleaje marino y una sensibilidad que roza el carácter orgánico del rococó, propio de escultores de cronología más avanzada.

Igualmente original es su manera de tallar las largas barbas de San Pablo, fórmula que identificamos también en la imagen de San Ginés de la Jara, del Paul Getty Museum, en Los Ángeles, la de San Nicolás de Bari, en Antequera (Málaga) o la del San Francisco de Paula, en Puerto Real (Cádiz) (fig. 8). El modelado no forma aquí surcos profundos entre los cabellos sino masas estriadas más sugeridas con los pinceles que talladas con las gubias, e interrumpidas de vez en cuando por ojales más profundos, de perfil sinuoso, que acentúan el efecto de claroscuro.

Ese importante papel de la policromía que no sólo colorea sino que sugiere y sustituye al mismo volumen convirtiéndose en factor tan protagonista como éste de los efectos finales que la obra produce, es un tercer rasgo muy peculiar de las esculturas de Luisa Roldán. Esto se percibe de forma especialmente nítida en la representación de los cabellos. Son muy llamativos, como en otras obras

\footnotetext{
si alguna de ellas procede de las arcillas del Guadalquivir o de las que debió usar en la Corte. De igual forma, al estar vaciadas ambas piezas con los propios dedos y no con la ayuda de vaciadores metálicos, podría permitir identificar las huellas dactilares de quien las modeló.
}

Arch. esp. arte, LXXXIX, 353, ENERO-MARZO 2016, 29-42

ISSN: 0004-0428, eISSN: 1988-8511, doi: 10.3989/aearte.2016.03 


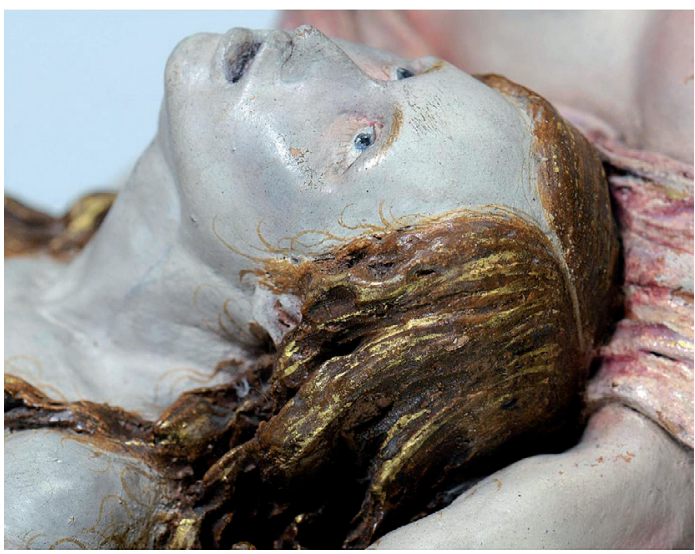

Fig. 9. Luisa Roldán. La muerte de María Magdalena. Hispanic Society of America. Nueva York. Detalle (Foto: Patrick Lenagham).

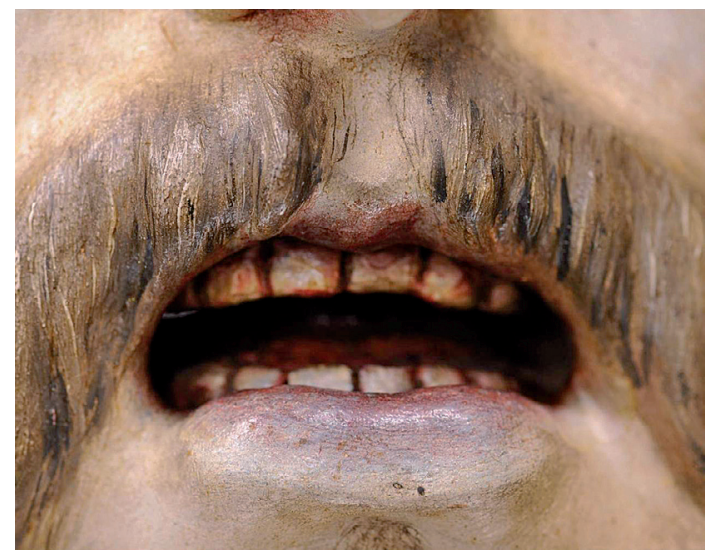

Fig. 10. Luisa Roldán. Cabeza de San Pablo. Hispanic Society of America. Nueva York. Detalle (Foto: Patrick Lenagham).

de La Roldana, los pelillos oscuros pintados sobre la piel nacarada, hechos uno a uno y produciendo una sensación de impactante realismo (fig. 7). Pero también los numerosos matices de la epidermis, a la que el pintor ha dado sombras, brillos o mortecinas y violáceas tonalidades, revela una labor semejante a la que Valdés Leal realizara en el grupo escultórico del Santo Entierro del Hospital de la Caridad, de Sevilla, tallado por Roldán. No es escultura simplemente cubierta de colores, es auténtica "pintura" realizada sobre un volumen. Es evidente que la formación del policromador era en este caso la de un pintor de obras de caballete que se ocupa aquí de esta labor y la desempeña con una suficiencia nada vulgar, logrando un "simulacro" convincente verdaderamente barroco.

También acostumbraba éste a dar sutiles pinceladas de oro líquido en los mechones de cabello, de color castaño. Este original método que logra dar mayor viveza a las cabelleras de sus personajes, se percibe en estas dos cabezas cortadas y también en el San Miguel del Escorial, el San José de Antequera, el Niño Nazareno de Granada y en numerosas figuras de sus grupos de terracota, entre otros, los de la propia Hispanic Society ${ }^{35}$ (fig. 9). Todos estos matices inducen a pensar que esta policromía está seguramente realizada por su cuñado Tomás de los Arcos, igual que la de San Miguel para el Escorial o la Virgen con el Niño y San Juanito, hoy en Chicago. Ambas obras fueron firmadas por la escultora y también por su policromador habitual al que concede así un protagonismo compartido digno de ser tenido en cuenta.

La boca abierta de ambos santos (fig. 10), dejando visibles las dentaduras superior e inferior por el desplome del abultado belfo, guarda una semejanza muy notable con la de la imagen de Jesús Nazareno de Sisante (Cuenca) ${ }^{36}$ (fig. 11), la del Ecce Homo de la catedral de Cádiz ${ }^{37}$ y, sobre todo, el de la cofradía de la Redención, en León ${ }^{38}$ (fig. 12).

Pero, si bien estoy persuadido de que Luisa Roldán pudo ser la autora de estas dos esculturas, nada sabemos con seguridad de las circunstancias concretas de su encargo ni tampoco de su pro-

${ }^{35}$ Desconozco si algún otro escultor de la corte acostumbraba a completar con toques dorados las cabelleras pero hasta el momento no he identificado a ninguno que lo practique entre los españoles y sí entre los escultores napolitanos algunas de cuyas obras pudo Luisa Roldán haber visto en España.

${ }^{36}$ Pleguezuelo, 2011: Fig. 5.

${ }^{37}$ Sánchez Peña, 1985-86: 329-338.

${ }^{38}$ Llamazares, 2009-2010: 85-93. 


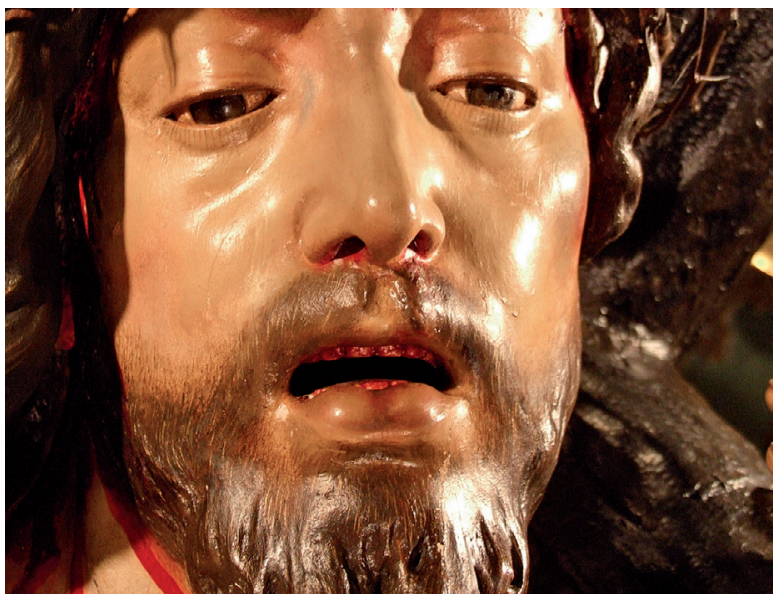

Fig. 11. Luisa Roldán. Jesús. Convento de Madres Franciscanas. Sisante (Cuenca) Detalle (Foto: Alfonso Pleguezuelo).

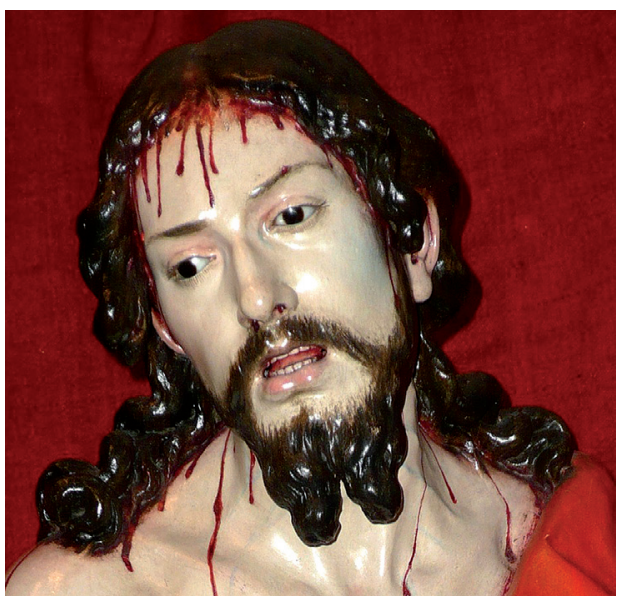

Fig. 12. Luisa Roldán. Ecce Homo. Depósito del Ministerio de Justicia e Interior en la Cofradía de Jesús de la Redención. León. Detalle (Foto: Fernando Llamazares).

veniencia inmediata al ingresar en la Hispanic Society ${ }^{39}$. Sólo atendiendo a su calidad, podemos asegurar que se trata de obras hechas para un cliente de relevancia, tal vez Juan Antonio Gutiérrez de Carriazo, padre de la citada Maria Manuela, además de caballero de Santiago, miembro del Consejo de Su Magestad en la Real Hacienda y Tesorero General de la Guerra, para Felipe V, de quien Luisa era escultora de Cámara. Y si prescindimos de las desconocidas circunstancias que rodean el encargo de estas dos obras, tampoco disponemos de información sobre el contexto físico o el simbólico en que se insertaban las esculturas de esta iconografía. Las mencionadas en el inventario de la citada familia estaban protegidas en sus "urnas", término que entonces designaba cualquier expositor de paredes transparentes. Es preciso mencionar aquí el relicario de cristal de roca, ébano y bronce, con la cabeza de San Juan en su interior, que la reina madre doña Mariana de Austria envió como regalo desde la Corte al monasterio sevillano de Santa Paula en 1694, justamente en los años en que la Roldana trabaja para su hijo Carlos II y la mujer de éste, Mariana de Neoburgo. ¿Podría ser aducido este hecho como testimonio de una devoción especialmente sentida en la familia real española de ese momento y en su entorno más cercano? Esculturas con el tema de la cabeza cortada de San Juan eran habituales en las colecciones privadas de familias españolas relevantes, según se aprecia en los inventarios de la época ${ }^{40}$.

Pero ¿cómo se representaban en la pintura? Si acudimos a los ejemplos pictóricos sevillanos de la segunda mitad del siglo XVII, las cabezas de San Juan y San Pablo aparecen en diferentes escenarios pero se percibe una tendencia a ubicarlas sobre una mesa - a veces cubierta con algún paño o con la túnica del santo- sobre la que también se posan los atributos. El fondo oscuro en las

\footnotetext{
${ }^{39}$ No hemos tenido oportunidad de consultar la correspondencia de Huntington en la que tal vez pudiera hallarse alguna noticia de la adquisición de la obra.

${ }^{40}$ Puede ser comprobado este extremo en Helmstutler y Coppel, 2013. Agradezco esta referencia bibliográfica a Patrick Lenaghan.
}

Arch. esp. arte, LXXXIX, 353, ENERO-MARZO 2016, 29-42

ISSN: 0004-0428, eISSN: 1988-8511, doi: 10.3989/aearte.2016.03 
obras del naturalismo temprano, tiende más tarde a mostrarse más iluminado y a incluir cortinajes de tela roja que conceden a la escena un aire teatral y el tono de un auténtica "naturaleza muerta", en este caso, no animal ni vegetal sino humana y con valor sagrado. Es muy revelador en este sentido un lienzo anónimo sevillano que se encuentra en la Gemäldegalerie Alte Meister, de Dresde y en que aparecen entre tales colgaduras y sobre platos dorados, las cabezas de San Juan, San Pablo y Santiago respectivamente. Todo en esa obra simula estar dispuesto para ser observado como una especie de sagrado banquete en los que están presentes el cuerpo y la sangre de los mártires aludidos.

Por otro lado, parece adivinarse también un cierto vínculo entre este tema y el culto sacramental de las celebraciones del Corpus Christi. Tal vez por esta razón la mencionada cabeza modelada por Gaspar Núñez y firmada en 1591, fue, tres años después de ser realizada, expuesta entre dos floreros, sobre la mesa de uno de los altares que jalonaban el recorrido de la custodia procesional de la iglesia Colegial de El Salvador de Sevilla ${ }^{41}$. Ello también nos hace recordar el principal banquete sagrado del ritual cristiano, la Eucaristía, celebración que conmemora la Última Cena de Jesús con sus apóstoles en que pide la difusión de su mensaje al tiempo que denuncia la traición de uno de sus seguidores.

Ese doble sentido profano/religioso, esa dúplice intencionalidad positiva/negativa, esa bipolar metáfora vida/muerte que se esconde detrás de tantos banquetes, son factores que se mezclan de manera compleja, profunda e inextricable en este impactante motivo de la iconografía cristiana. La muerte por decapitación, un acto violento tan antiguo como el propio ser humano, puede estar originada por múltiples motivaciones y posee diferentes significados que discurren desde la agresión bélica a la pena judicial, pasando por la venganza personal y por incontables circunstancias concretas. Los dos casos históricos que aquí han sido mencionados tuvieron lugar durante los tiempos del Imperio Romano y se enmarcaron en situaciones diferentes aunque estuvieron unidos por una circunstancia común, el carácter martirial que revistieron ambas ejecuciones al estar motivadas por la defensa del naciente pensamiento judeocristiano, en abierta oposición al paganismo ${ }^{42}$.

La narración figurativa de estas dos muertes cruentas suele resumirse en el arte cristiano desde fines de la Edad Media y durante la Edad Moderna en la sintética representación de las cabezas cortadas de ambos personajes, sustituyéndose así la descripción completa de sus respectivas historias por la imagen escueta de su fatal desenlace en una especie de sinécdoque icónica de enorme impacto emocional y, por tanto, de gran eficacia comunicativa.

Si nos preguntamos por el sentimiento que estas obras producen en el espectador actual, muchos responderían que es de horror y repugnancia a pesar de que resultan, si cabe, aún más crudas que éstas, muchas de las imágenes que se nos muestran en los medios de comunicación que informan sobre los crímenes de guerra o las venganzas del narcotráfico, por cierto muy inclinadas estas últimas a emplear la vieja costumbre de la "poena capitis". Pero si, con un sentido más histórico, nos esforzamos por pensar cuál sería la reacción de los creyentes del siglo XVII ante estas obras, tal vez habría que añadir otros contenidos justificativos de la extraña atracción-repulsión que generaban escenas de tal dureza: ¿la admiración por el héroe que ofrece su vida por la defensa de una idea? ¿la conmiseración por el dolor infringido tan cruelmente? ¿el morboso y paradójico placer de una era, la barroca, que algún autor ha calificado de "melancólica" en el sentido más depresivo, enfermizo y autodestructivo del término ${ }^{43}$

En un reciente artículo, Arellano resalta la importancia del tema de las cabezas cortadas en el teatro del Siglo de Oro español, en especial, en la obra teatral de Calderón, por cierto, madrileño, caballero santiaguista y servidor del rey, como el cliente de Luisa Roldán ${ }^{44}$. En él alude a estudios de antropólogos que han reflexionado sobre la violencia como un elemento básico y permanente

\footnotetext{
${ }^{41}$ Véase para este asunto Palomero, 2005: 204.

${ }^{42}$ Mommsen, 1999: 360 y ss.

${ }_{43}$ De la Flor, 2007.

44 Arellano, 2014: 199-213.
}

Arch. esp. arte, LXXXIX, 353, ENERO-MARZO 2016, 29-42 ISSN: 0004-0428, eISSN: 1988-8511, doi: 10.3989/aearte.2016.03 
en la historia de la cultura humana y, por tanto, en la historia del arte ${ }^{45}$. Arellano alude igualmente a las cabezas cortadas como objetos que formaban parte del cotidiano atrezzo teatral de las tragedias y comedias de nuestro Barroco; enseres ejecutados en varios materiales ligeros como el cartón o el cuero y que perseguían provocar admiratio en los espectadores. Los españoles y las españolas del siglo XVII tal vez hallarían en estas obras la excusa para estimular el "don de lágrimas" que tanto fomentaban los teólogos de la época y con el que los creyentes manifestarían su dolor por la pérdida de estos varones ejemplares.

Concluye su artículo Arellano con el siguiente párrafo: Si como es de suponer, al público barroco le gustaban no menos que al del siglo XXI las truculencias y morbosidades, en el teatro de Calderón tenía buena oportunidad de experimentar la insana atracción de la crueldad y el delicioso escalofrío del horror ${ }^{46}$.

Es obvio que la vida de nuestros artistas barrocos se desenvolvía en este mismo ambiente de violencias más o menos sublimadas que respiraban nuestras ciudades. Las obras de arte, se apoyen tanto en la palabra como en la imagen, tienen siempre móviles comunes y ofrecen respuestas muy semejantes; sólo varía la óptica a través de la que dichas expresiones son contempladas al cabo de los años y las argumentaciones de quienes, como nosotros, pretendemos vanamente explicarlas.

\section{BIBLIOGRAFÍA}

Agulló y Cobo, Mercedes (1981): Más noticias sobre pintores madrileños de los siglos XVI al XVIII, Madrid Ayuntamiento de Madrid.

Alonso Moral, Roberto (2010): "La producción de escultura en barro del Manierismo al primer Naturalismo: Gaspar Núñez Delgado y los Hermanos García”. En: Gila Medina, Lázaro (coord.), La escultura del primer naturalismo en Andalucía e Hispanoamérica (1580-1625), Madrid, pp. 533-356.

Anónimo (1898): “Cabeza de San Pablo", (Museo Arqueológico de Valladolid) Sección de Bellas Artes. En: Boletín de la Sociedad Española de Excursiones, Vol. 6, n 66-68, p. 134.

Arellano Ayuso, Ignacio (2014): “Cabezas cortadas y otros espectáculos: violencia, patetismo y truculencia en el teatro de Calderón”. En: Melanges de la Casa de Velázquez, n 44, pp. 199-213.

Baert, Bárbara (2013): “The Johannesshüssel as andachtsbild: the gaze, the médium and the senses". En Catrien Santing, Baert / Anita Traninger: Disendbodied Heads in Medieval and Early Modern Culture, Brill, Leiden-Boston, pp. 117-160.

Barrio Moya, José (1989): “La biblioteca y otros bienes de D. Julián Moreno de Villoda, secretario mayor del Ayuntamiento de Madrid durante los reinados de Felipe V y Fernando VI (1751)". En: Anales del Instituto de Estudios Madrileños, $\mathrm{n}^{\circ}$ 27, pp. 605-616.

De la Flor, Fernando (2007): Era melancólica. Figuras del imaginario barroco. Palma: José J. de Olañeta, Editor y Universitat de les Illes Balears.

Dobado Fernández, Juan (2009): «Un Nacimiento desconocido de la Roldana». En: Myriam. Revista Mariana Universal, Sevilla, Año LXI, n 365, pp. 196-197.

Flavio Josefo (2002): Antigüedades judías, 2 vols. Madrid: Akal.

Gestoso, José (1909): Ensayo de un diccionario de los artífices que florecieron en Sevilla del siglo XIII al XVIII. Sevilla, pp. 150-151.

Gestoso, José (1917): Biografía de un pintor sevillano, Juan Valdés Leal, Sevilla.

Girard, René (1983): La violencia y lo sagrado, Barcelona.

Gregori, Mina (2007): "La trayectoria del tema desde Leonardo hasta Caravaggio: la Cabeza de San Juan Bautista”. En: In Sapientia libertas. Escritos en homenaje al profesor Alfonso Pérez Sánchez, MadridSevilla, pp. 353-364.

Helmstutler Di Dio, Kelley / Coppel, Rosario (2013): Sculpter Collections in Early Modern Spain. Farnham: Ashgate.

${ }^{45}$ Girard, 1983: 23 citado por Arellano, 2014 nota 2.

46 Arellano, 2014: 212.

Arch. esp. arte, LXXXIX, 353, ENERO-MARZO 2016, 29-42

ISSN: 0004-0428, eISSN: 1988-8511, doi: 10.3989/aearte.2016.03 
Herrera García, Francisco / Pérez de Tena, Ana (2011): "Un San José con el Niño atribuido a la Roldana en el convento de Santa María la Real de Bormujos, Sevilla". En: Atrio, no 17, pp. 59-68.

Kinkead, Dunkan (1986): "La danza de Salomé". En: Archivo Español de Arte, n 233, pp. 82-83.

Llamazares Rodríguez, Fernando (2009-2010): “Un nuevo Ecce Homo de la Roldana, y el mensaje teológico de esta iconografía en la escultura barroca española". En: Boletín de Arte, no 30 Málaga, pp. 89-95.

Luna Delgado, Luis (2008-2009): "Gaspar Núñez Delgado y la escultura de barro en Sevilla". En: Laboratorio de Arte, 21, pp. 379-394.

Martín González, Juan José (1957): “Cabezas de santos degollados en la escultura barroca española”. En: Goya, $\mathrm{n}^{\circ} 16$, pp. 210 y 213.

Martínez Ripoll, Antonio (1978): Francisco Herrera,"el viejo”. Sevilla: Excma. Diputación.

Mommsen, Teodoro (1999): El derecho penal romano. En: La España Moderna, Volumen II, Madrid, 1905, Ed. Facsímil Pamplona, pp. 360 y ss.

Pacheco, Francisco (1990): Arte de la pintura, (edición al cuidado de Bonaventura Bassegoda i Hugas), Madrid: Cátedra.

Palomero Páramo, Jesús (2005): "La cultura artística de la ciudad de la giganta (Notas sobre pintores y escultores en la Sevilla de Cervantes). En: Núñez Roldán, Francisco (coord.): La ciudad de Cervantes. Sevilla, 1587-1600, Sevilla: Ayuntamiento de Sevilla-Fundación El Monte, pp.199-221.

Pleguezuelo, Alfonso (2009): "El Niño del Dolor, obra de Luisa Roldán. Una confirmación documental". En: Archivo Hispalense, $\mathrm{n}^{\circ}$ 279-281, pp. 27-53.

Pleguezuelo, Alfonso (2011a): "Los inciertos comienzos de una obra de Luisa Roldán, Jesús Nazareno de Sisante (Cuenca)". En: Fernández Gracia, Ricardo (coord.) Pulchrum. Scripta Varia in Honorem $M^{a}$ Concepción García Gaínza. Pamplona: Gobierno de Navarra y Universidad de Navarra, pp. 634-642.

Pleguezuelo, Alfonso (2011b): "Cuatro belenes inéditos de la Roldana". En: Ars Magazine, Revista de arte y coleccionismo, Año IV, $\mathrm{n}^{\circ}$ 0, pp. 80-93.

Pleguezuelo, Alfonso (2012): "Luisa Roldán y el retablo sevillano". En: Laboratorio de Arte, no 24, Universidad de Sevilla, no 275-300, pp. 27-53.

Proske, Beatrice G. (1930): Catalogue of Sculpture (Thirteenth to Fifteenth Centuries) in The Collection of The Hispanic Society of America, The Hispanic Society of America. Nueva York.

Proske, Beatrice G. (1938): The Hispanic Society of America Handbook. Museum and Library Collentions. Nueva York.

Proske, Beatrice G. (1954): A History of Hispanic Society of America, Museum and Library (1904-1954) with a Survey of the Collections. Nueva York.

Proske, Beatrice G. (1964): "Luisa Roldán at Madrid”. En: The Connoisseur, February-April.

Reau, Louis (1995): Iconografía del arte cristiano. Tomo I, Vol. 1, Barcelona, pp. 510-518.

Requena Bravo de Laguna, José Luis (2012): "Princeps Monachorum. Arte e iconografía de San Juan Bautista en los siglos del Barroco Hispano". Tesis Doctoral inédita, dirigida por el Prof. Dr. Ricardo Fernández Gracia, Pamplona Universidad de Navarra.

Roda Peña, José (2012): Pedro Roldán, escultor 1624-1699. Madrid: Arco-Libro S.L.

Romero Torres, José Luis (2009): "The education of the Virgin" y "Saint Joseph and the Child". En: Cat. Exp. The Mystery of the Faith. An eye on Spanish Sculpture 1550-1750. Londres: The Matthiesen Gallery/Coll y Cortés Gallery, pp. 166-179.

Romero Torres, José Luis / Torrejón Díaz, Antonio (comisarios) (2007): cat. exp., Roldana. Sevilla: Consejería de Cultura, Junta de Andalucía.

Sánchez Peña, José Miguel (1985-86): "El Ecce Homo de la catedral de Cádiz, obra de Luisa Roldán”. En: Cuadernos de arte, XVII, Granada, pp. 329-338.

Sancho Corbacho, Heliodoro (1950): El escultor sevillano Pedro Roldán y sus discípulos, Sevilla.

Stratton, Suzanne L. (ed.) (1993): Spanish Polychrome Sculpture 1500-1800 in United States Collections, cat. exp. Nueva York: The Spanish Institute.

Valdivieso, Enrique (comisario) (1991): Valdés Leal, cat. exp. Sevilla-Madrid: Junta de Andalucía-Museo del Prado.

Valdivieso, Enrique (2000): Pintura barroca sevillana. Sevilla: Ed. Guadalquivir.

Fecha de recepción: 04-VI-2014

Fecha de aceptación: 16-XII-2014

Arch. esp. arte, LXXXIX, 353, ENERO-MARZO 2016, 29-42 ISSN: 0004-0428, eISSN: 1988-8511, doi: 10.3989/aearte.2016.03 